\title{
PEMBUATAN INFUS ELEKTRONIK RUMAH SAKIT
}

\author{
Hermawan Suprayogi ${ }^{1 *}$, Istiadi $^{2}$, Gigih Priyandoko $^{3}$ \\ ${ }^{1,3}$ Program Studi Teknik Elektro, Fakultas Teknik, Universitas Widyagama Malang \\ ${ }^{2}$ Program Studi Teknik Informatika, Fakultas Teknik, Universitas Widyagama Malang \\ *Email Korespondensi : hermawan.suprayogi@gmail.com
}

\begin{abstract}
ABSTRAK
Infus merupakan suatu peralatan rumah sakit atau klinik yang berfungsi untuk memberikan makanan (nutrisi) ataupun obat dalam bentuk cairan kepada pasien dalam kurun waktu yang sudah ditentukan oleh Dokter. Penelitian ini bertujuan untuk mengembangkan sistem pengaturan dan pemantauan tetesan cairan infus dengan sensor photodioda dan kendali motor servo secara Internet Of Things. Sensor TCRT5000 digunakan untuk mendeteksi tetesan cairan infus dan mikro motor servo digunakan untuk menjepit selang infus yang akan mengatur jumlah tetesan infus. Konsep IOT telah ditetapkan untuk membangun sistem ini dan berhasil memantau tetesan cairan infus melalui internet. Pengujian sistem dilakukan untuk mengatur jumlah tetesan per menit. Hasil pengujian menunjukkan bahwa sistem telah mampu mengatur dan memantau tetesan cairan infus dengan rata-rata kesalahan sebesar $1,14 \%$ sampai $3,2 \%$.
\end{abstract}

Kata Kunci : Internet of Things, tetesan infus, kendali mikro servo, TCRT5000.

\section{ABSTRACT}

Infusion is a hospital or clinic equipment that functions to provide food (nutrition) or medicine in the form of liquid to patients within a period determined by the doctor. This study aims to develop a system of regulation and monitoring of drip liquid droplets with photodiode sensors and servo motor control in the Internet of Things. TCRT5000 sensors are used to detect droplets of intravenous fluids and micro servo motors used to clamp the infusion hose, which will regulate the number of drip drops. The concept of IoT has been established to build this system and has successfully monitored the droplets of intravenous fluids through the internet. System testing is done to regulate the number of droplets per minute. The test results show that the system has been able to regulate and monitor liquid drip droplets with an average error of $1.14 \%$ to $3.2 \%$.

Keywords : Internet Of Things, infusion, infusion droplets, servo micro controls, TCRT 5000

\section{PENDAHULUAN}

Infus merupakan suatu peralatan rumah sakit atau klinik yang berfungsi untuk memberikan makanan (nutrisi) ataupun obat dalam bentuk cairan kepada pasien dalam kurun waktu yang sudah ditentukan oleh dokter. Di Indonesia masih banyak rumah sakit dan klinik yang masih menggunakan peralatan manual untuk mengatur jumlah tetesan cairan infus per menitnya. Petugas medis atau perawat masih harus menghitung jumlah tetesan infus dengan melihat jam sealma satu menit (Muljodipo, 2015; Silalahi, et al., 2016).

Pada umumnya, pengaturan jumlah tetesan infus yang dilakukan secara manual ini memiliki beberapa gangguan atau masalah, diantaranya jumlah tetesan yang lebih atau kurang dari standart, cairan infus macet atau berhenti, naiknya darah ke selang infus dan juga cairan infus yang habis tanpa diketahui oleh perawat. Salah satu kasus dari gangguan tersebut adalah seringnya cairan infus yang habis tanpa diketahui oleh perawat. Apabila hal ini tidak ditangulangi dengan cepat,maka pasien akan kekurangan cairan (Dehidrasi).

(Aditya, 2014; Anggraini, et al., 2011; Anggraini \& Adil, 2011; Adil, 2011) pernah merancang sebuah alat yang berfungsi untuk memonitoring tetesan infus yang masuk ke tubuh pasien dengan cara meletakkan sebuah sensor photodioda sebagai saklar untuk menghitung jumlah tetesan infus per menit nya. Alat ini hanya memantau tetesannya saja dan ditampilkan pada grafik sistem visual basic. Alat ini tidak dilengkapi dengan sistem 
pengaturan jumlah tetesan cairan infus. (Muljodipo, 2015; Nataliana, et al., 2016; Moses, 2017) juga pernah merancang alat monitoring dan pengatur jumlah tetesan infus dengan sensor photodioda sebagai sensor tetesan infus dan mikro servo sebagai pengendali laju tetesannya. Namun Untuk pengontrol utamanya adalah mikrokontroler AVR ATMega16. Bahasa pemograman yang digunakan untuk memprogram adalah CodeVision AVR Evaluation V2.05. Namun alat ini tidak dilengkapi dengan sistem yang ada pada PC atau Android yang bisa digunakan untuk memonitoring secara realtime atau terus menerus. (Anggraini \& Adil, 2011) juga sudah mengaplikasikan idenya dalam bentuk alat pengatur jumlah tetesan infus sesuai resep dokter. Yang mana pada alat ini dokter atau perawat memasukkan nilai atau jumlah tetesan infus di awal pemasangannya dan alat ini dapat memantau jumlah tetesan per menit dengan sistem yang ada pada PC dokter. Komunikasi yang digunakan untuk menghubungkan alat dengan sistem yang ada pada PC dengan menggunakan kabel serial RS232. Untuk komunikasi membutuhkan kabel yang panjang jika jarak ruang pasien dengan ruang dokter terlalu jauh. Sehingga alat ini terlihat kurang efektif.

Dari beberapa penelitian yang dilakukan diatas, masih ada beberapa kekurangan dalam segi pengaplikasian seperti pengaturan yang dilakukan secara manual dan juga pemantauan tetesan infus tidak dapat dilakukan dengan jarak jauh oleh perawat atau dokter. Oleh karena itu pada penelitian kali ini akan dibuat sebuah alat pemantauan dan pengaturan tetesan cairan infus dengan sensor photodioda dan kendali motor servo secara Internet of Things. Cara kerja alat ini adalah dokter atau perawat memasukkan set poin jumlah tetesan infus yang diperlukan pasien per menitnya baik dengan tombol maupun sistem Delphi 7.0 dan dokter atau perawat akan melihat perkembangan jumlah tetesan infus per menit yang ada pada LCD 16 x 2, sistem Delphi 7.0 yang ada pada PC/Laptop ruang perawat atau dokter serta dapat memantau kondisi tetesan infus jarak jauh via android dengan sistem Thing speak secara Internet of Things. Kelebihan utama dari alat ini dilengkapi dengan sistem Thing speak atau (Internet of Things) untuk komunikasi data pemantauan tetesan cairan infus. Dokter juga akan mengetahui apabila cairan infus dalam botol akan habis dengan led indikator sebagai alarmnya serta progres bar untuk volume larutan pada sistem Delphi. Sehingga dengan adanya alat ini, kondisi infus dapat di kontrol dan dipantau dengan mudah oleh dokter atau perawat rumah sakit.

\section{METODE}

Kebutuhan fungsional dari pengaturan dan pemantauan tetesan cairan infus ini adalah sistem mampu mengatur tetesan infus dari tombol, sistem mampu mengatur tetesan infus dari aplikasi desktop, sistem mampu memantau tetesan infus dan ditampilkan di LCD, sistem mampu memantau tetesan infus dan ditampilkan pada aplikasi desktop, sistem mampu memantau tetesan infus dan ditampilkan pada android, dan sistem mampu memantau kondisi cairan infus.

Perancangan sistem dalam penelitian kali ini dibagi kedalam dua jenis yaitu perancangan perangkat keras (Hardware) atau perancangan perangkat lunak (Software). Perancangan perangkat keras digunakan untuk merancang sistem mulai dari perancangan blok diagram dan cara kerja alat. Blok diagram perancangan hardware dapat dilihat pada Gambar 1. Perancangan perangkat lunak digunakan untuk merancang tampilan sistem baik pada sistem Delphi 7.0 dan pada ThingSpeak, perencanaan program dan flow chart cara kerja alat. Flow Chart cara kerja alat dapat dilihat pada Gambar 2.

Dalam perancangan perangkat keras atau hardware membutuhkan beberapa komponen pendukung mulai elektronik hingga perlengkapan mekanik agar sistem dapat bekerja dan berjalan dengan baik sesuai dengan fungsinya. Agar mudah dipahami maka dibuat diagram blok dan alur kerjanya.

Sesuai dengan Gambar 1, dapat dilihat bagaian-bagian yang membentuk sistem. Adaptor $5 \mathrm{Vdc}$ merupakan catu daya untuk memberikan tegangan kepada Modul Arduino Nano, tombol, sensor TCRT5000, HC-12 Transmitter, HC-12 Receiver, LCD 16 x 2, LED 
Alarm dan Mikro servo SG-90. Tombol berfungsi untuk memilih settingan TPM (Tetesan/menit). Sensor TCRT 5000 (Tetesan infus) berfungsi sebagai input yang bertujuan untuk menghitung jumlah tetesan infus yang terjadi, kemudian hasil pembacaan akan diolah oleh Arduino Nano (Silalahi, et al., 2016). Pengendali yang digunakan adalah Modul Arduino Nano, yang mana modul ini akan mengolah data input berupa jumlah tetesan infus yang di baca oleh sensor TCRT5000, kemudian akan memerintahkan mikro servo untuk menekan selang infus dan hasill pembacaan sensor akan di tampilkan melalui aplikasi desktop pada PC server atau Android (Lawa, 2017). NodeMCU ESP8266 berfungsi untuk mengirimkan data TPM dari arduino ke Thingspeak yang nantinya TPM akan dipantau via Android. Mikro servo SG-90 berfungsi sebagai penekan dari selang infus untuk mengatur laju tetesan infus (Nataliana, 2016). Untuk komunikasi pengiriman data dari Arduino nano ke PC server menggunakan HC-12 . HC-12 (Transmitter) adalah modul radio frekuensi untuk menghubunhgkan atau mengirimkan data secara Nirkabel yang akan di terima oleh HC-12 (Receiver). HC-12 (Receiver) adalah modul radio frekuensi untuk menerima data secara Nirkabel yang akan di tampilkan oleh aplikasi desktop pada PC/Laptop. LCD 16x2 sebagai output yang berfungsi sebagai tampilan atau display yang nantinya akan menampilkan menu settingan TPM dan hasil aktual TPM. LED alarm adalah LED output yang berfungsi sebagai indikator jiika terjadi alarm terkait tetesan infus yang tidak menetes atau level infus yang rendah. HP android berfungsi untuk menammpilkan grafik atau pantauan jumlah tetesan infus yang dihasilkan dalam satu menit.

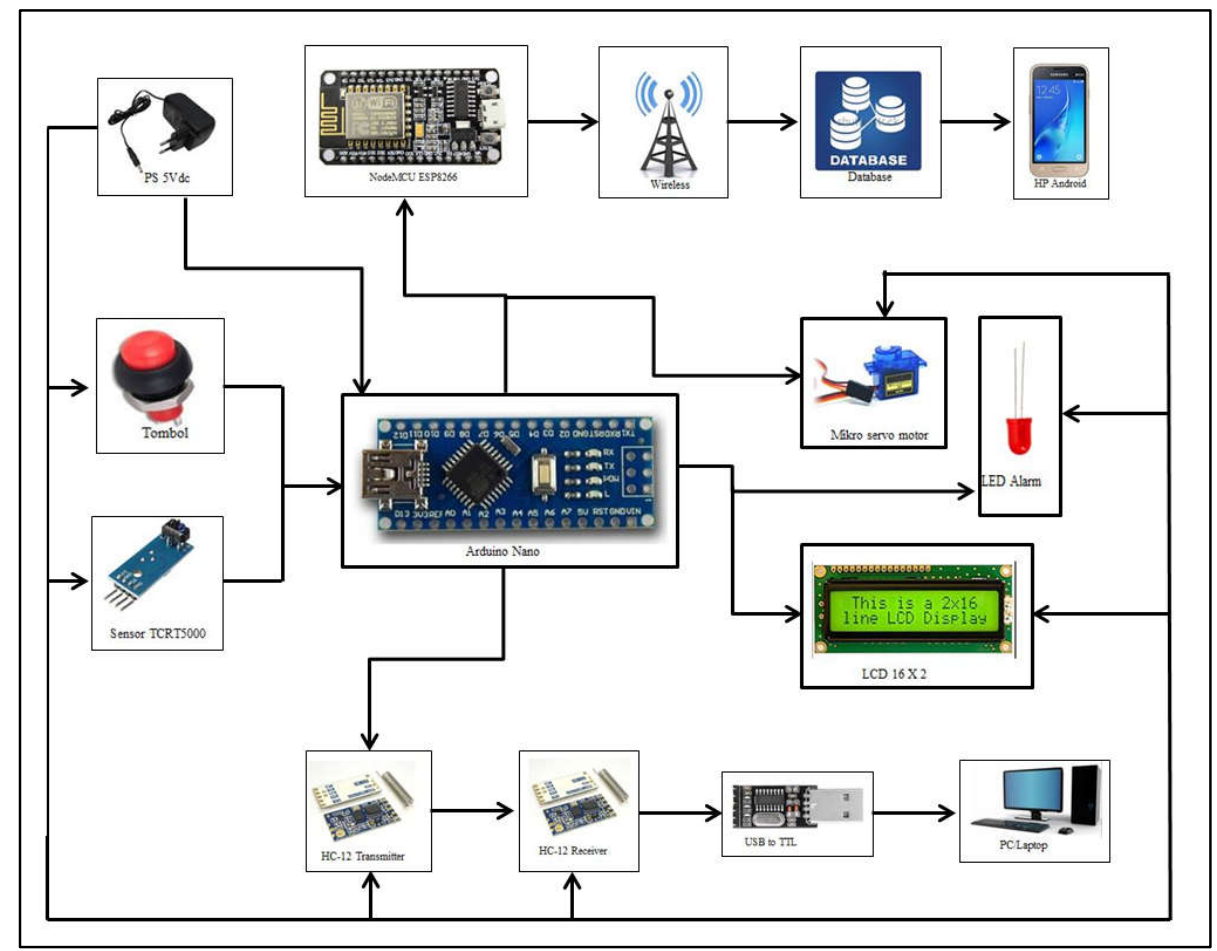

Gambar 1. Blok diagram perencanaan Hardware

Perancangan perangkat lunak atau software dilakukan untuk merencanakan sistem atau cara kerja alat pengaturan dan pengaturan tetesan cairan infus. Seperti yang terlihat pada gambar 2, sistem kerja dari alat ini pertama alat ini akan menghentikan laju tetesan infus agar tidak ada tetesan sebelum dilakukannya setting nilai TPM baik dari tombol atau dari aplikasi desktop. Kemudian lakukan settingan TPM baik dari tombol atau dari aplikasi desktop. Alat akan membuka selang infus sesuai dengan settingan yang diberikan. Jika dalam kurun waktu 
satu menit alat mendeteksi adanya tetesan infus, maka hasil TPM akan ditampilkan pada LCD. Kemudian disaat yang bersamaan data TPM akan dikirim pada PC dan Thingspeak untuk dilakukan pemantauan TPM jarak jauh. Namun, jika dalam kurun waktu satu menit alat tidak mendeteksi adanya tetesan infus, maka led alarm akan menyala sebagai indikator jika ada masalah pada alat. Alat juga akan mengecek kondisi infus melalui progress bar yang mana akan menghitung jumlah tetesan yang terjadi. Jika level cairan infus habis atau tinggal $50 \mathrm{ml}$, maka akan mengaktifkan LED alarm sebagai indikatornya. Alat akan memantau tetesan terus menerus apabila alat tidak dimatikan. Jika alat dimatikan maka semua sistem akan berhenti.

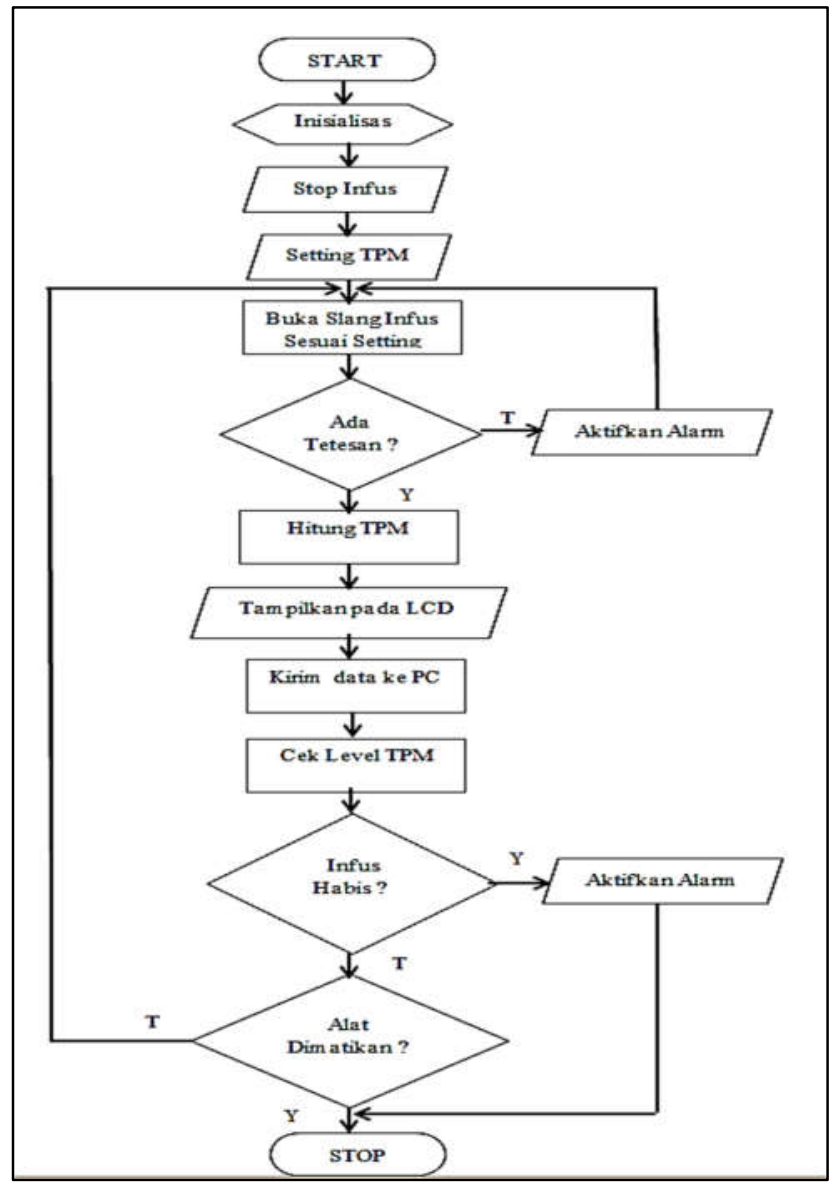

Gambar 2. Flow chart diagram alur cara kerja alat.

\section{HASIL DAN PEMBAHASAN}

Proses pengaturan tetesan cairan infus dapat dilakukan melalui tombol dan juga dapat dilakukan melalui aplikasi dekstop. Jumlah TPM (tetesan/menit) yang dihasilkan akan ditampilkan pada aplikasi desktop dan juga ThingSpeak pada HP android berdasarkan perubahan pemantauan TPM.

Pengujian keseluruhan sistem dengan megabungkan semua perangkat keras meliputi arduino nano, nodemcu esp8266, hc-12, tcrt5000, tombol, lcd 16x2 dan juga usb to ttl. Arduino Nano digunakan untuk mengontrol sistem mekanik dan juga mengirimkan data pada Delphi secara nirkabel menggunakan HC-12. Sedangkan NodeMCU ESP8266 digunakan sebagai modul wifi yang nantinya akan mengirimkan data Tetesan per menit secara Internet 
of Things. Alat ini dapat mengatur jumlah TPM (Tetesan per Menit) dari dua tempat yang berbeda yakni dari tombol yang terdapat pada box LCD dan juga dapat mengatur secara nirkabel pada aplikasi desktop PC/laptop. Hasil TPM akan ditampilkan dari tiga tempat yang berbeda, mulai dari LCD, sistem yang ada pada Delphi dalam bentuk grafik dan juga Thingspeak dalam bentuk grafik. Hasil perangkaian dari USB to TTL dengan HC-12 dapat dilihat pada Gambar 3.

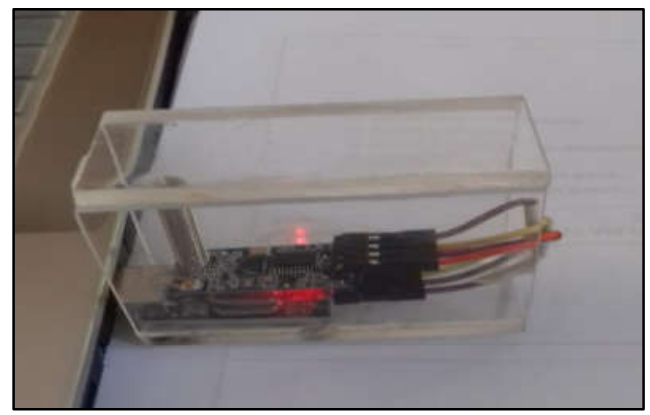

Gambar 3. Hasil Rangkaian USB to TTL dengan HC-12.

Hasil perangkaian sistem mekanisme penjepitan selang dan penempatan sensor TCRT5000 dapat dilihat pada Gambar 4.

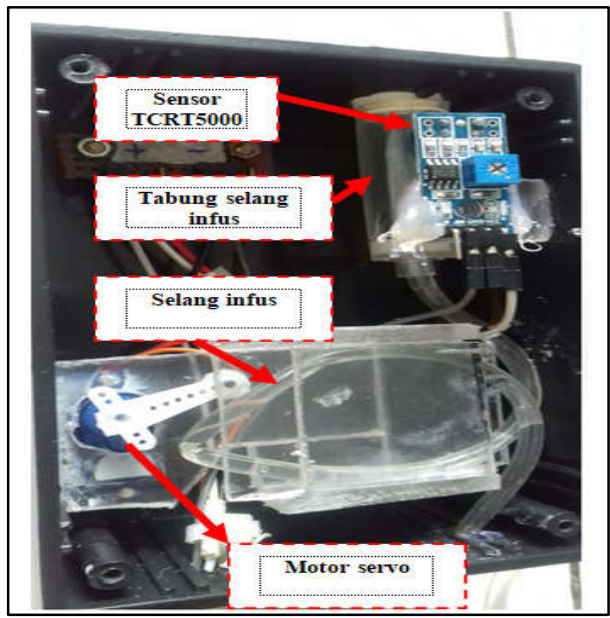

Gambar 4. Hasil Rangkaian mekanisme penjepitan

Sesuai dengan Gambar 4, dapat dilihat bagaian-bagian yang membentuk sistem mekanis. Sensor TCRT5000 akan mendeteksi adanya tetesan infus dengan jarak kurang dari satu $\mathrm{cm}$ dari tabung selang infus. Apabila sensor tcrt5000 mendeteksi adanya tetesan maka akan berlogika 1 yang nantinya data akan dikirimkan kepada Arduino nano. Selang infus didesain sedemikian rupa agar motor servo dapat menjepit selang infus sesuai dengan settingan TPM yang diberikan. Motor servo akan bergerak ke kanan untuk menekan selang infus dan akan bergerak ke kiri untuk melonggarkan selang infus. Sesuai Gambar 5 dapat dilihat tampilan keseluruhan alat pengaturan dan pemantauan insfus. Setelah semua komponen dirangkai, maka bisa dilakukan pengujian pengaturan TPM baik dari tombol maupun dari aplikasi desktop PC/Laptop. Alat ini terdiri dari satu buah infus kemasan 500 $\mathrm{ml}$, mekanis sistem penjepitan infus dan box kontroller yang terdiri dari tampilan LCD, LED alarm dan tombol untuk setting TPM.

Sebelum melakukan setting TPM melalui aplikasi desktop, hal yang harus dilakukan adalah menguji seberapa jauh jarak jangkauan komunikasi dari HC-12. Pengujian perangkat 
keras HC-12 dilakukan untuk mengetahui bahwa sistem HC-12 dapat difungsikan sebagai Receiver (penerima) dan juga dapat diaplikasikan sebagai Transmitter (pengirim). HC-12 Berfungsi sebagai media komuniasi antara perangkat ke sistem delphi 7.0. Untuk setting HC12 kita menggunakan software arduino IDE. Jika HC-12 difungsikan sebagai receiver, maka memerlukan USB to TTL untuk mengkonfersi level tegangan TTL menjadi level tegangan USB sehingga bisa dibaca oleh komputer. Pengujian HC-12 dilakukan didalam ruangan (indoor) dan dilakukan diluar ruangan. Hasil pengujian jarak jangkauan Transmitter ke Receiver baik indoor atau outdoor dapat dilihat pada Tabel 1.

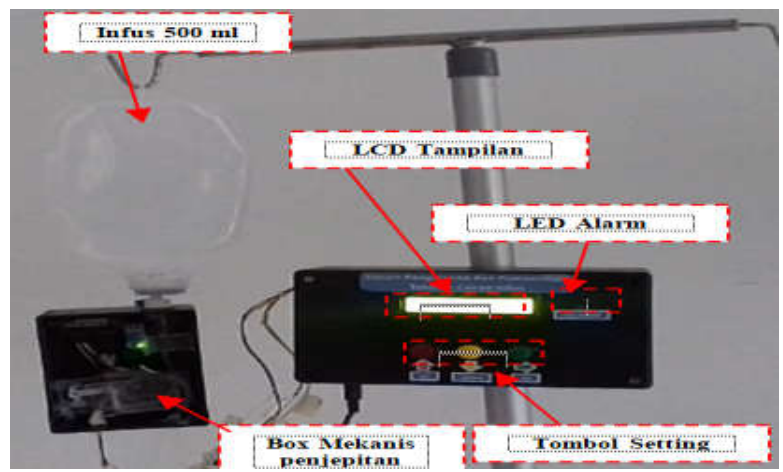

Gambar 5. Tampilan dari Alat Keseluruhan

Tabel 1. Pengujian jarak jangkauan Transmitter ke Receiver

\begin{tabular}{|c|c|c|c|c|}
\hline No. & Jarak (meter) & Data Kirim & Status & Pengujian \\
\hline 1 & 10 & TES & Terkirim & \multirow{7}{*}{ Indoor } \\
\hline 2 & 20 & TES & Terkirim & \\
\hline 3 & 30 & TES & Terkirim & \\
\hline 4 & 40 & TES & Terkirim & \\
\hline 5 & 50 & TES & Terkirim & \\
\hline 6 & 60 & TES & Sulit Terkirim & \\
\hline 7 & 70 & TES & Tidak terkirim & \\
\hline 8 & 20 & TES & Terkirim & \multirow{12}{*}{ Outdoor } \\
\hline 9 & 40 & TES & Terkirim & \\
\hline 10 & 60 & TES & Terkirim & \\
\hline 11 & 80 & TES & Terkirim & \\
\hline 12 & 100 & TES & Terkirim & \\
\hline 13 & 120 & TES & Terkirim & \\
\hline 14 & 140 & TES & Terkirim & \\
\hline 15 & 160 & TES & Terkirim & \\
\hline 16 & 180 & TES & Terkirim & \\
\hline 17 & 200 & TES & Terkirim & \\
\hline 18 & 220 & TES & Sulit Terkirim & \\
\hline 19 & 240 & TES & Tidak Terkirim & \\
\hline
\end{tabular}

Dari hasil Hasil pengujian jarak jangkauan Transmitter ke Receiver dilakukan pengukuran setiap 10 meter secara indoor dan 20 meter secara outdoor sesuai Tabel 1 menunjukkan jarak aman komuniksi indoor adalah sejauh 50 meter dan jarak aman komunikasi outdoor adalah 200 meter.

Cara mengatur TPM dengan tombol digunakan apabila seorang dokter atau perawat ada pada ruang pasien dan biasanya dilakukan pada saat awal pemasangan cairan infus pada pasien. Hasil pemantauan pada sistem ini akan ditampilkan pada LCD 16 X 2 yang akan ada keterangan "Setting TPM" dan juga "Aktual TPM. Keterangan Setting TPM akan menunjukkan nilai TPM yang akan di setting. Sedangkan keterangan Aktual TPM akan menunjukkan hasil pemantauan TPM secara terus menerus sesuai hasil pembacaan sensor TCRT5000. 
Selain cara pengaturan dan pemantauan tetesan cairan infus, alarm infus juga sangatlah penting. Dimana alarm infus ini digunakan untuk mengetahui apabila kondisi level cairan infus sudah tinggal $50 \mathrm{ml}$ dan juga untuk memantau TPM yang tidak mengalir dalam kurun waktu 60 detik. Hal ini akan menimbulkan efek kurang baik kepada pasien. Dokter atau perawat dapat mengetahuinya dengan adanya Led indikator dan keterangan pada LCD akan ada keterangan "Cek Infus" untuk mengecek kondisi infus pasien. Tombol dan LCD untuk pengaturan dan pemantauan tetesan infus serta LED alrm bisa dilihat pada Gambar 6 .

Cara mengatur TPM dengan Aplikasi desktop digunakan apabila seorang dokter atau perawat ada pada ruang dokter. Setelah cairan infus dipasang oleh perawat kepada pasien, Dokter tidak perlu lagi datang keruang pasien untuk melakukan pengaturan TPM. Komunikasi pengiriman data ini menggunakan HC12. Hasil TPM akan ditampilkan pada sebuah grafik yang mana data TPM akan ditampilkan selama sistem terhubung dengan perangkat seperti pada Gambar 6.

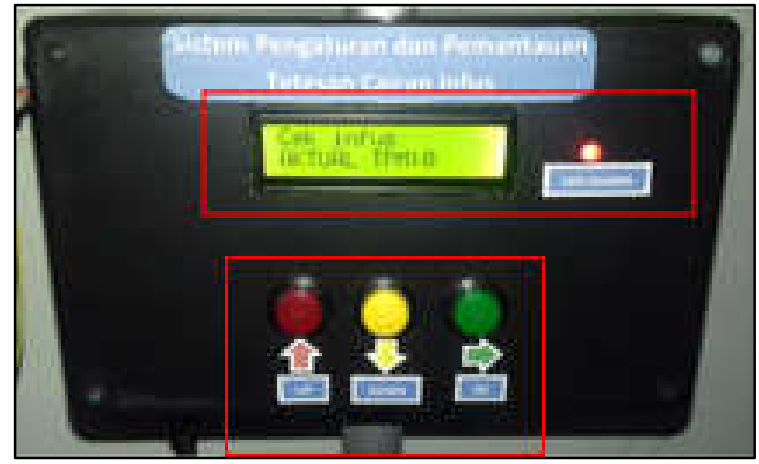

Gambar 6. Tampilan Tombol dan LCD untuk mengatur dan memantau jumlah TPM

Pada aplikasi desktop juga akan terpantau level cairan infus dengan adanya tampilan progres bar. $1 \mathrm{ml}$ cairan infus sama dengan 20 tetesan infus, sehingga dalam kemasan 500 $\mathrm{ml}$ cairan infus akan menghasilkan kurang lebih 10.000 TPM. Sistem ini dirancang apabila kondisi level cairan infus tinggal $50 \mathrm{ml}$, maka keterangan pada progress bar sama dengan 1000 TPM. Tampilan Aplikasi desktop untuk mengatur dan memantau jumlah TPM serta tampilan progres bar level cairan infus dapat dilihat pada Gambar 7. Untuk dapat menghubungkan antara perangkat dengan IOT pada aplikasi android, dokter atau perawat terlebih dahulu login pada web server ThingSpeak. Sehingga ThingSpeak akan memantau terus menerus jumlah tetesan infus. Adapun cara login bisa dilihat pada Gambar 8 .

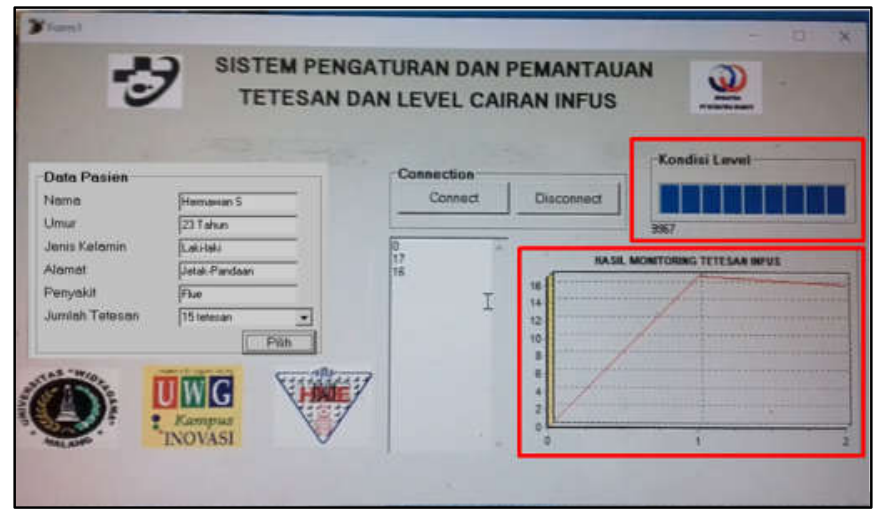

Gambar 7. Sistem Delphi untuk mengatur dan memantau jumlah TPM serta memantau level cairan infus 


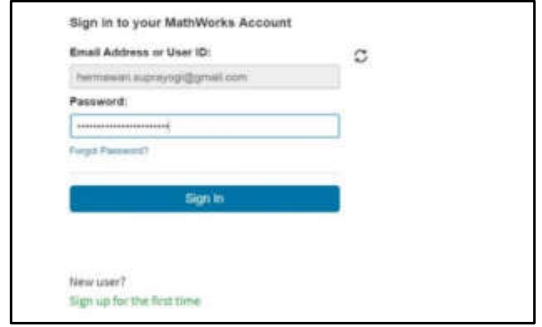

Gambar 8. Tampilan android untuk Login aplikasi

Cara memantau kondisi TPM infus secara Internet of things bertujuan agar dokter atau perawat dapat memantau kondisi terkini tetesan infus pasien melalui HP atau android. Dalam hal ini hasil TPM akan ditampilkan secara grafik, sehingga dokter dapat lebih mudah memantau kondisi infus pasien. Tampilan pemantauan TPM dapat dilihat pada Gambar 9 dibawah ini:

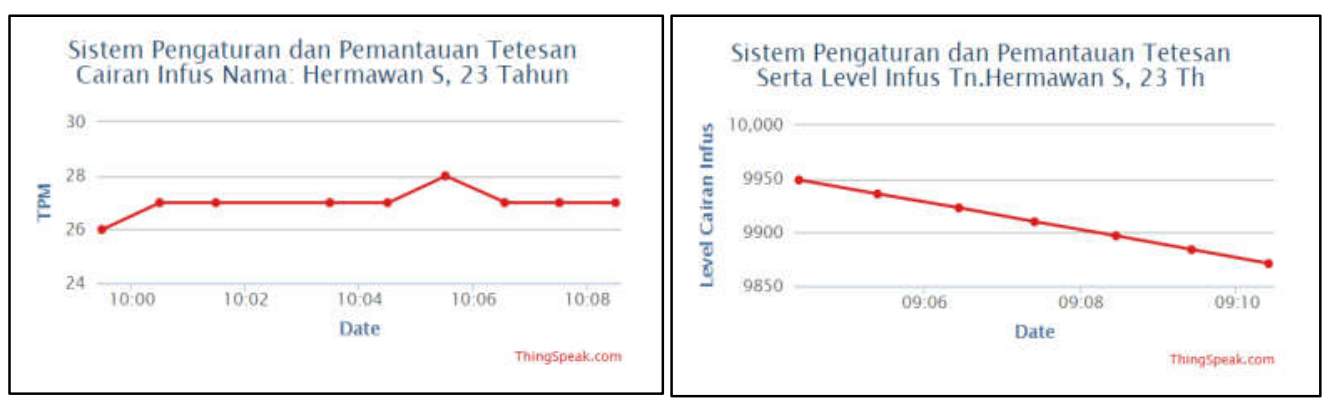

Gambar 9. Tampilan monitoring TPM dan Level Cairan infus dengan aplikasi android.

Pada aplikasi android juga akan terpantau level cairan infus dengan adanya tampilan grafik. Dalam kemasan $500 \mathrm{ml}$ cairan infus akan menghasilkan kurang lebih 10.000 TPM. Sehingga kondisi level infus dapat diketahui dengan pengurangan dari level infus keseluruhan dikurangi aktual TPM, dan hasilnya akan ditampilkan pada grafik kondisi level cairan infus. Sehingga dokter atau perawat dapat mengetahui level infus tinggal $50 \mathrm{ml}$ dengan jumlah cairan kurang lebih 1000 TPM.

Sekitar $60 \%$ dari berat badan manusia adalah cairan. Tak heran bila setiap sistem di dalam tubuh memerlukan air untuk menjalankan fungsinya. Yakni untuk melembapkan tenggorokan, hidung, dan telinga,membawa nutrisi dari sel ke sel, dan sebagainya. Orang dewasa membutuhkan sekitar 2,5 L per hari untuk pria. Sedangkan untuk wanita dewasa sekitar 2,3 L air perhari (T. Rina Yunita, 2017).

Berdasarkan berat badan pasien, jumlah kebutuhan cairan dapat dihitung sebagai berikut (Satria, 2017) :

a. Berat badan $<10 \mathrm{~kg}=100 \mathrm{~mL} / \mathrm{kgBB}$

b. Berat badan $10-20 \mathrm{~kg}=1000+50 \mathrm{~mL} / \mathrm{kgBB}$ untuk setiap kilogram berat badan di atas $10 \mathrm{~kg}$

c. Berat badan $>20 \mathrm{~kg}=1500+20 \mathrm{~mL} / \mathrm{kgBB}$ untuk setiap kilogram berat badan di atas $20 \mathrm{~kg}$

Dari rumus jumlah kebutuhan cairan pada pasien diatas, maka berikut adalah cara menghitung TPM (Tetesan/menit) sesuai rumus dasar menghitung jumlah tetesan cairan dalam satuan menit (A. Aditya, 2014):

$$
\text { Jumlah Tetesan Per Menit }=\frac{\text { Jumlah Kebutuhan Cairan x Faktor Tetes }}{\text { Waktu (Menit) }}
$$

Berdasarkan rumus kebutuhan cairan dalam tubuh manusia dan rumus perhitungan jumlah TPM diatas, maka dapat dihitung ketentuan setting TPM cairan infus kemasan 500 
ml baik untuk Balita, anak-anak dan Dewasa dalam sehari . Tabel untuk contoh ketentuan setting TPM dapat dilihat pada Table 3.

Tabel 3. Contoh Ketentuan seting TPM berdasarkan berat badan untuk $500 \mathrm{ml}$ infus dalam sehari.

\begin{tabular}{|c|c|c|c|c|}
\hline No. & Berat Badan & Kategori & Kebutuhan Cairan & TPM (+/-2 tetes) \\
\hline 1 & 10 & Balita & 1000 & 14 \\
\hline 2 & 15 & Anak-anak & 1800 & 25 \\
\hline 3 & 50 & Dewasa & 2500 & 35 \\
\hline
\end{tabular}

Dari tabel di atas maka pada pengujian pengaturan TPM dilakukan sebanyak 5 kali percobaan dengan settingan jumlah 15, 25 dan 35 tetesan/menit. Untuk settingan 15 TPM digunakan untuk balita dengan berat badan kurang dari $10 \mathrm{~kg}$ dengan kebutuhan cairan kurang lebih 12-16 TPM dalam sehari. Untuk settingan 25 TPM digunakan untuk anak-anak dengan berat badan kurang dari $20 \mathrm{~kg}$ dengan kebutuhan cairan kurang lebih 23-27 TPM dalam sehari. Sedangkan untuk settingan 35 TPM digunakan untuk orang dewasa dengan berat badan kurang dari $50 \mathrm{~kg}$ dengan kebutuhan cairan kurang lebih 33-37 TPM dalam sehari. Pengujian ini dilakukan untuk mengetahui apakah sistem dapat berfungsi atau tidak, serta untuk mencari rata-rata error pada tiap tetesan cairan per menit.

Berikut ini adalah hasil pengujian otomatis sistem infus pasien secara keseluruhan untuk semua pilihan settingan yang dapat dilihat pada Tabel 4. Dari hasil pengujian diatas maka didapat rata-rata tetes/menit pada pengaturan 15 tetes/menit adalah 14,2 tetes. Dengan rata-rata persentase kesalahan sebanyak 1,33\%, pada pengaturan 25 tetes/menit adalah 25,8 tetes. Dengan rata-rata persentase kesalahan sebanyak 3,2\% dan pada pengaturan 35 tetes/menit adalah 34,6 tetes. Dengan rata-rata persentase kesalahan sebanyak 1,14\%.

Tabel 4. Hasil pengaturan 15, 25, dan 35 tetes/menit

\begin{tabular}{|c|c|c|c|c|}
\hline No & Setting TPM & Aktual TPM & Error $(\ldots \%)$ & Rata-Rata \\
\hline 1 & 15 & 14 & $6,60 \%$ & \multirow{5}{*}{$1.33 \%$} \\
\hline 2 & 15 & 16 & $6,60 \%$ & \\
\hline 3 & 15 & 14 & $6,60 \%$ & \\
\hline 4 & 15 & 15 & $0 \%$ & \\
\hline 5 & 15 & 15 & $0 \%$ & \\
\hline 6 & 25 & 26 & $4 \%$ & \multirow{5}{*}{$3.2 \%$} \\
\hline 7 & 25 & 27 & $8 \%$ & \\
\hline 8 & 25 & 25 & $0 \%$ & \\
\hline 9 & 25 & 25 & $0 \%$ & \\
\hline 10 & 25 & 26 & $4 \%$ & \\
\hline 11 & 35 & 33 & $5.71 \%$ & \multirow{5}{*}{$1.14 \%$} \\
\hline 12 & 35 & 34 & $2.85 \%$ & \\
\hline 13 & 35 & 36 & $2.85 \%$ & \\
\hline 14 & 35 & 35 & $0 \%$ & \\
\hline 15 & 35 & 35 & $0 \%$ & \\
\hline
\end{tabular}

Dari ketiga pengujian diatas, dapat diketahui bahwa waktu yang dibutuhkan utuk mendapatkan hasil TPM sesuai dengan yang di setting adalah kurang lebih 3-4 menit. Alat ini juga sudah mampu mengatur dan memantau tetesan serta level cairan infus secara internet of things (IOT), sehingga dapat mempermudah perawat atau dokter dalam mengatur dan memantau kondisi infus pasien di rumah sakit.

\section{DAMPAK DAN MANFAAT}

Kebutuhan pengendalian dan pengaturan jarak jauh dalam mengidentifikasi volume cairan infus menginspirasi penelitian dan perancangan sistem informasi berbasis android 
dengan sistem dan Internet of Things. Sistem informasi ini sangat berguna dan bermanfaat bagi dokter jaga dan perawat untuk mengtahui kebutuhan infus pasien, dalam hal ini, dokter jaga dan perawat dapat memantau dari jauh dan mengidentifikasi ketersediaan cairan infus. Dengan kata lain, dokter jaga dan perawat dapat mengetahui sesegera mungkin cairan infus yang akan habis dan segera menggantinya. Kelebihan utama dari alat ini dilengkapi dengan sistem Thing speak atau (Internet of Things) untuk komunikasi data pemantauan tetesan cairan infus. Dokter juga akan mengetahui apabila cairan infus dalam botol akan habis dengan led indikator sebagai alarmnya serta progres bar untuk volume larutan pada sistem Delphi. Sehingga dengan adanya alat ini, kondisi infus dapat di kontrol dan dipantau dengan mudah oleh dokter atau perawat rumah sakit

\section{KESIMPULAN}

Penelitian ini telah berhasil membangun dan mengimplementasikan alat pemantauan tetesan infus per menit secara Internet of Things dengan menggunakan sensor TCRT5000 dengan jarak kurang dari $1 \mathrm{~cm}$ dengan rata-rata kesalahan sensor antaran $1.14 \%$ sampai $3,2 \%$. Alat ini juga dapat digunakan untuk mengatur dan memantau tetesan cairan infus baik dilokasi pasien dengan tombol, ruang perawat atau dokter Aplikasi desktop dengan jarak aman jangkauan HC-12 untuk komunikasi indoor 50 meter sedangkan outdoor 200 meter, dan dapat dipantau dengan jarak jauh dengan HP android dengan sistem Thing Speak. Sehingga dapat memudahkan kinerja perawat atau dokter dalam mengatur dan memantau tetesan infus pasien.

\section{UCAPAN TERIMA KASIH}

Ucapan terima kasih ditujukan kepada Jurusan Teknik Elektronika Kosenrasi Energi Listrik, Fakultas Teknik, Universitas Widyagama Malang.

\section{DAFTAR PUSTAKA}

Aditya, A. (2014) 'Cara Cepat Menghitung Tetesan Infus', http://www.argaaditya.com/2014/03/cara-cepat-menghitung-tetes-infus.html

Anggraini, D. F., Adil, R., Rochmad, M. dan Susetyo, P. W. (2011) 'Pengembangan Sistem Monitoring Tetesan Infus Pada Ruang Perawatan Rumah Sakit', EEPIS, Final Project.

Anggraini, D. F. dan Adil, R. (2011) 'Pengembangan Sistem Monitoring Tetesan Infus Pada Ruang Perawatan Rumah Sakit', Biomed. Eng. 6.

Nataliana, D., Taryana, N. dan Riandita, E. (2016) 'Alat Monitoring Infus Set pada Pasien Rawat Inap Berbasis Mikrokontroler ATmega 8535', Jurnal Elkomika. 4(1).

Moses, L. (2017) 'Rancang Bangun Alat Pemantau Tetes Infus dan Suhu Badan dengan Tampilan Digital Berbasis Arduino Uno', Skripsi, UKSW.

Muljodipo, M. (2015) 'Rancang Bangun Otomatis Sistem Infus Pasien', E J. Tek. Elektron. Dan Komput. 4(4). 11-17.

Silalahi, P., Ramadhani, A. dan Fashia, R. A. (2016) 'Monitoring Cairan Infus Menggunakan Radio Frekuensi FS1000A', Tek. Umsida, 6-12.

Adil, R. (2011) 'Alat Bantu Monitoring Rate Jantung, Suhu Tubuh dan Kontrol Tetesan Infus Pada Ruang Perawatan Rumah Sakit', Biomed. Eng., 6-14. 